\title{
Discussion and Analysis on Xi Jinping's Theory of Ideology
}

\author{
Chuyi Gao \\ School of Marxism \\ Wuhan University of Science and Technology \\ Wuhan, China 430065
}

\begin{abstract}
The thoughts and theories of General Secretary Xi Jinping are important parts of Marx's thought as well as the guiding thought of the construction of ideological safety. This paper has researched the theoretical basis of Xi Jinping's theory of ideology and has concluded the main opinions and methods in the theory of ideology from the important addresses of General Secretary $\mathrm{Xi}$ Jinping, proposing the countermeasures and development paths according to the new characteristics and difficulties of the ideological development in the new period.
\end{abstract}

Keywords-Xi Jinping; ideology; theory

\section{INTRODUCTION}

Marxism-Leninism, Mao Zedong thought and the theoretical system of socialism with Chinese Characteristics have been regarded as the scientific propositions as well as the core contents of the current mainstream ideology in China. They are scientific judgments that have been acknowledged and the core contents of China's mainstream ideology at present. The ideological theory of $\mathrm{Xi}$ Jinping firmly and organically integrates the three, ceaselessly getting rid of the stale and bringing forth the fresh from an overall perspective in the deepening and development.

\section{MAIN CONTENTS OF THE IDEOLOGICAL THEORY OF XI JINPING}

The marked feature of ideological work since the 18th National Congress of CPC is to adhere to the consciousness of problems and problem orientation. In face of the complicated international and domestic environment, General Secretary Xi Jinping bases on the experience and wisdom of leaders in all ages, standing at a historical height and clearly proposing, "At present, the connotation and denotation of national security of our country are richer than any other time in history, the domain of time and space is wider than any other time in history, and the internal and external factors are more complicated than any other time in history". The three "than any other time in history" is the scientific analysis and strategic research and judgment of the national security environment in the ideological sphere of our country at present. As an important part of the national security, the ideological safety also faces severe and diversified challenges. Therefore, General Secretary Xi Jinping has given keynote speeches for many times, addressing his strategic thought of ideology, the main contents of which include the following aspects:

\section{A. Make the Position and Primary Task of the Ideological Work}

According to the importance and the special status of the ideological work, General Secretary Xi Jinping specially observes on the national conference on the ideological propaganda, "The ideological work is an extremely important work of the Party". He proposes the construction of the ideological work concerns the development prospect of the Communist Party of China and has a distinctly important influence on the long-term stability and governance of the socialist country China and the great unity of Chinese nation. The result has been repeatedly proved by history and reality on long-term basis. Meanwhile, he also emphasizes we must grasp the "three rights"- speaking right, leadership right and management right in determining the status of ideological work. General Secretary Xi Jinping thinks the ideological work will inevitably face the irretrievable errors if the government and the Party fail to grasp the three rights. On the basis of grasping the status quo of ideology, General Secretary $\mathrm{Xi}$ Jinping reveals the basic, strategic and overall position of the ideological work, proposing the primary and important problem of "why".

Marxism is the fundamental ideological guarantee and guidance of national stability, social solidarity, economic development and people's happiness as well as the theoretical basis for the unity and development and progress of people nationwide. At present, anti-Marxism thoughts and nonMarxism thoughts sweep, publicizing the Marxism "has been outdated", the guiding thought must be "diversified" and advocating "only constitutional democracy can save China and the Marxism causes damages to the national interest". The incredible opinions and thoughts are widely reported, severely threatening the development of socialist ideology in our country at present. Under this circumstance, General Secretary $\mathrm{Xi}$ Jinping emphasizes in the important address of the national conference on the ideological propaganda, "the ideological propaganda is to consolidate the guiding role of Marxism in the ideological sphere and the common ideological basis for the solidarity and struggle of the Party and the people". The important judgment systematically elaborates the major issue about "what to do" in the ideological work. 


\section{B. Expound the Start Point and the Basic Principle of Ideological Work}

Party character and people's character are the important theory and practical problems in the ideological sphere, concerning the nature and direction of the ideological work. General Secretary Xi Jinping proposes, "The Party character and people's character are consistent and unified", expounding the cardinal stand of the ideological work from the aspect of fundamental nature. Insisting on the Party character means adhering to people's interests, adhering to the mass line and adhering to deciding for the people, so the Party character and people's character have consistency fundamentally. The connotation of the Party character is contained in the latter. The important opinion of General Secretary Xi Jinping reaffirms the Communist Party adheres to the principle of unification of the Party and the people, clarifying the problem in the vague understanding about the relationship between the Party and people, better reflecting the idea of the Party and the people's expectation in the new historical conditions.

For the basic policy of the ideological work, General Secretary Xi Jinping profoundly proposes, "the ideological propaganda must follow the important policy of insisting on unity and stability and encouragement as well as positive publicity". In face of the new characteristics of the ideology in our country at present, we must be brave to confront the unprecedented difficult problems and dilemma and can never abandon the theme and the diffusion of the positive energy. We must publicize in a big way and regard it as the primary way of the basic policy. At the meantime, General Secretary $\mathrm{Xi}$ also observes, "Adhering to the positive publicity does not mean abandoning the struggle in public opinion". When the noise in the ideological sphere obviously increases in face of the current social thought and enthusiasm, General Secretary says we must timely pay attention to the development trend of the public opinion, discover and deeply analyze the specific social problems and improve the identification ability; we must use the scientific truth to guide the ideological and political work, strengthen the management and control of opinions on the hostile attack of China's leading group and social system, investigate and treat in accordance with the law; firmly implement the responsibility system of ideological work, help cadres and audiences to distinguish the limit of right and wrong and clarify the vague opinions; we must have a firm attitude in the matters of principle and grasp the initiative. Instead of waiting for the treatment of problems negatively, we must take the initiative to solve all kinds of problems. The methods on the ideological work fully expound the problem about "how to do" in the ideological work.

\section{Emphasize the Key Points and the New Methods of the Ideological Work}

At present, the internet has become the main battlefield of public opinion warfare. Under this circumstance, General Secretary Xi Jinping proposes on the first conference of the center leading group on the network security and informatization in 2014, "we must pay high attention to establishing the social governance system of network and guarantee the ideological safety of network at the same time continuously strengthen the ability to guarantee the network security". The address shows the new layout of the ideological work in our country at present shall focus on the network security. Xi Jinping emphasizes the network security and the high development of electronic information help each other and bring out the best in each other, requiring the vigorous advancement of the development of network and telecom industry and the maintenance of network safety. At the level of ideology, he requires us to establish the good and positive security concept in the network to lead the work of network security; at the level of system guarantee, he emphasizes we must strengthen the security assurance of the infrastructure of network and telecom and drive the overall development systematically, strengthen the force of defending the network safety; at the level of network environment, he proposes we must build the healthy network ecological environment and lead the public opinions through using its atmosphere, reflecting conditions and the will of the people. The positive and healthy network environment and the positive network atmosphere will transmit the positive energy in socialist and build a clear space for the net citizens, which avail the network construction of the ideological safety in our country and the publicity of public opinions.

We must adhere to the innovative thinking in the ideological work. General Secretary Xi Jinping proposes in the address on Aug.19, "We must make efforts to open the new situation of work through the new leap of ideological understanding and actively explore the new measures and new methods to solve problems in work". The implementation of the ideological work requires us to give full play to the innovative thinking, actively explore the problems that have disturbed the ideological construction for a long time and solve them through innovative thinking and means. The implementation of the innovative work includes three aspects: The first is the concept innovation. We can not follow the beaten track ideologically but break through the traditional thinking and solve single problem through the open and overall thinking and open the new situation and trend of the ideological work; the second is the innovation of means. We fully combine the methods of the ideological work with the newest achievements of science and technology and strengthen the thinking of "Internet Plus", using the newest media method and adopting the means and methods that we cannot think and achieve in the past in the publicity, grasping the initiative of information transmission; the third is to innovate in the grassroots work. We should base on the grass roots and the benefit of the working people, pay attention to the role of grass-roots people and organization, solidly laying foundation for the grass-roots work and providing the basic and powerful guarantee for other ideological work.

\section{Seize the Depending Strength and Position of the Ideological Work}

General Secretary Xi Jinping proposes, "The ideological propaganda must be implemented by all the party members", requiring the joint efforts of the Communist Party in conducting the ideological work. The whole Party must assume the responsibilities in completing the ideological propaganda. First, on the contents of the work, we must integrate the ideological propaganda in all fields of the daily 
work, closely combining the national governance and the ideological publicity to realize the all-round penetration; second, the scope of work must completely cover the central and the grass-roots party organization, strengthening and implement the responsibility mechanism, letting all the party organizations and party members participate in the ideological propaganda; third, we must deepen the importance of ideology in the learning contents of the Party and make efforts to train a batch of leading cadres, strengthening the cognition and cultivation of the ideological work in learning and practice; finally, the ideological propaganda must spread to the masses through party members. The good relation between the party and the masses can be used to accelerate the speed of the ideological construction, letting the radiation range of the ideological work extend from the whole party to the whole society and the whole country. The ideological propaganda is a systematic engineering, which can be realized through coordination and collaboration. It's not enough to only depend on the propaganda department. The whole party must participate and the party committees at all levels shall assume responsibilities. The propaganda idea can be realized and the propaganda pattern can be shaped when the whole party and the people make efforts to achieve the same goal and aim at the same goal.

Media is the main channel for the diffusion of the mainstream ideology and the basic carrier and way for the mainstream ideology to realize its functions. Whether the media can positively and actively publicize the mainstream ideology directly concerns the direct results of the ideological work, as well as the main battlefield to consolidate the ideological work. Therefore, the supervision and management of media has always been the key to implement the ideological work. According to the characteristics in the new period, General Secretary Xi Jinping emphasizes on the forum of the party's press work, "The most fundamental principle of the party's press work is to insist the leadership of the press work. The media of the party and the government is the propaganda position of them, which must be under the leadership of the party". The basic principle of our country in the relationship between the party and the media in the ideological sphere is "the party leads the media". On one hand, without the leadership of the party, the media will lose the direction forward in the chaotic ideology and will fail to provide the correct and advanced guidance of public opinion for the society and the masses; on the other hand, the party must use the advantages and characteristics of the advanced media and present the mainstream ideology to the masses with different forms, contents and levels, grasping the development direction and removing the wrong and chaotic idea and opinion. Meanwhile, they must conduct the press work and strengthen the consciousness of battlefield, keeping the position of public opinions.

\section{TO DEVELOP AND IMPLEMENT THE OPINION OF XI} JINPING ON THE IDEOLOGY UNDER THE CURRENT SITUATION

\section{A. The Outstanding Features of Problems in the Ideological Sphere in Our Country at the New Period}

1) International: The ideological safety is always an important part of the national safety. In the development of history, western capitalist countries never give up the penetration and destroy of the socialist ideology. After the end of Cold War and the collapse of the Soviet Union, they turn to China. Before the millennium, a famous American think bank proposed the "three-step" plan for the Clinton Administration, directing the spearhead at China. They plan to "westernize" China on the aspect of ideology and disorganize the socialist system of China to achieve the goal of "dominate the world". During the past 17 years, western countries never slow down the attack on the ideology of our country. The penetration of the western value system is increasingly strong. Today, it has severely threatened the safety of China in the ideological sphere. The new characteristics of western countries in attacking the ideology are as follows:

The forms are more and more varied. According to the current situation of the social and economic development in China, western capitalist countries transform the core of the ideological invasion from military and politics to economy and culture gradually. Depending on its advanced science and technology and the advanced media, they divide and disorganize the ideological safety of China through various forms and means. They advocate the "universal value" and "constitutional democracy" and publicize "China Threat Theory", distorting the socialist core value system; they vigorously implement the values of liberalism and hedonism contained in the cultural products of capitalist, propagandizing and guiding it through electronic games, films and books; they collude with the reactionary force inside and outside China and create a contradiction and conflict to overturn the Chinese sovereignty and unity; they make the best of the new network media to distort and overstate the social phenomenon and deliberately irritate the net citizens to fight. Western capitalist countries weaken and attach the socialist ideology of China through continuously using the new forms and methods.

The means is more and more hidden. Compared with the means of vigorously propaganda and advocacy at early times, in recent years, the penetration ways and means of western value system are more hidden. Instead of vigorous propaganda, western countries always adopt the way of "agent", inciting some high level intellectuals and scholars and celebrities at home and making them deliberately speak contrary. The western value systems diffuse with these people as the center. However, western countries only provide funds and channels of communication in the dark. On one hand, they can "keep out of the affair" and let people pay attention to the "agent"; on the other hand, they can sow dragon's teeth to achieve the goal not to be divulged. In addition, in recent years, western countries and their "agents" advocate the historical nihilism, which replaces the way of directly criticizing the socialist system in the past, paying attention to historical events and historical figures, defending the reactionists but bringing 
shame on heroic figures in history, in order to let the masses doubt the history and reduce the public trust of the government and the party.

The objects are more comprehensive. With the advanced science and technology and the media, the western capitalist countries transform the objects whose ideology is attacked from the previous intermediate stratum directly to the grassroot class and the masses. The disguised network and the rapid diffusion avail them to easily realize the all-round penetration. They directly transmit the western capitalist values and the anti-Marxist social thoughts to the masses.

2) Domestic: The ideological safety in the new period also suffers from the threats at home. The development of the socialist market economy changes the material life of people and liberates the spiritual life of the masses. With the ceaseless transformation of economic system and the continuous deepening of the economic globalization, the ideology of people changes increasingly, becoming diversified on the whole. The development of modern media and the technology cover up the nature and intention of the penetration of western ideology. In this process, the outlook on life, values and the world outlook of the masses in our country are unconsciously influenced and greatly impacted. Specifically speaking, their political conviction is weakened, the value orientation is deflected and the way of act is inappropriate.

On the other hand, our country fails to markedly strengthen the cognition on the importance of maintaining the mainstream ideology, falling behind others in the propaganda of the mainstream ideology. The means and ways of propaganda are traditional, outdated, simple and unified. The guidance of the mainstream media and public opinion is inefficient. We fail to propagandize the mainstream values according to the development situation of the actual life of the masses. The traditional Chinese culture is an important carrier of the ideology, and its rich forms are gradually weakened and decomposed; the ideas advocated by the socialist core value system are eroded by the thoughts in capitalist society represented by pragmatism and hedonism, gradually reflecting on the behaviors and attitudes of the masses on dealing with affairs. It has greatly shaken the safety of the mainstream ideology.

\section{B. Ways to Explore the Ideological Safety in Our Country under the New Circumstances}

1) Firmly insist on the core of Marxist ideology: The theory of Marxism ideology has an extremely strong vitality and still guides the development of the mainstream ideology and the work and life of the masses in our country today. As the latest achievement of the Marxist ideology, the ideological theory of $\mathrm{Xi}$ Jinping must first firmly grasp the core and consolidate its guiding role in the ideological sphere fundamentally. In face of the penetration of such social thoughts as anti-Marxist and non-Marxist, we must firmly resist the wrong ideas, insisting the classical theories of Marx and Engels and continuously practicing and updating its age meaning in Chinese society under development, developing the classical thoughts with a dynamic thinking and firmly insisting the core.

2) The construction of internal and external environment to guarantee the ideological safety: As one of the important contents of the superstructure, the ideological safety is restricted by economic base and is influenced by other superstructures. Therefore, maintaining the implementation and development of the ideological theory of Xi Jinping must depend on the construction of internal and external environment that can guarantee the ideological safety. The good internal and external environment and the material basis can promote the positive and healthy development of thoughts and ideas.

Externally, we need a safe and stable state power and a strong international image to improve the sense of security and self-confidence of the masses. A stable state power is the most basic guarantee of people's production and life as well as the fundamental premise for the economic, political and cultural development of society. A strong international image can improve and maintain the international standing and the speaking right of a country and the people, making people have self-confidence and a sense of stability in the spiritual level as well as the material civilization. Therefore, we must firmly maintain the state sovereignty and severely strike the behaviors that overturn the state sovereignty and separatist forces; strengthen the construction of the national defense and military and defend the state sovereignty and the ideological safety of our country through the powerful armed forces. Under the current circumstance, we shall firmly defend the sovereignty of our country in the South China Sea and the core benefits of our country.

Internally, our country must actively advance the construction of political civilization and provide a good system safeguard for the ideological safety of our country through the "four-pronged comprehensive" strategy. Treat people as the master and solve the most important, the most advanced and the most concerned practical problems of them; insist the rule of law to guarantee the rights and obligations of people in our country; insist the leadership of the party and continuously strengthen the construction of the Party in all aspects, vigorously develop and improve the democratic political system of our country and promote the construction of the political civilization at the same time provide better system safeguard for the ideological and political construction.

On the other hand, as an important part of the socialist superstructure in our country, the traditional Chinese culture is inseparable from the socialist ideology, referring to an important carrier of the ideology. Therefore, we must inherit and develop the essence of the traditional culture in our country and let the public further acknowledge the national culture, creating and carrying forward as well as cultivating the social atmosphere of the traditional culture. Meanwhile, we must accelerate the modernization of the traditional culture and carry forward the socialist core value system of the traditional culture and morality to safeguard the ideological safety of our country. 
3) Strengthen the development of the ideological and political education in the new period: As the main and the most crucial way to propagandize and develop the mainstream ideology in our country, the ideological and political education shall have new characteristics and changes that adapt to the era in the new period. Different ways and means must be used in propaganda and education for people at different ages and class; schools and teachers must change the educational concept, reform the ideological and political education and replace the traditional "duck-stuffing" type of education with the new science and technology. Instead of the simple theoretical explanation, they must let the masses and students independently choose and contrast the differences between different ideologies, spontaneously realizing the superiority and advancement of the socialist ideology; the opinions and attitudes expressed by the mainstream ideology must be reflected in social phenomenon and mass unexpected incidents that attract people's attention, in order to make the mainstream ideology effective and pertinent.

4) Develop the modern media and grasp the speaking right in ideology:Media is the main position for the propaganda of ideology. In the new period, we must firmly grasp its development and contribute to the diffusion and propaganda of the mainstream ideology. At the meantime, we must enormously construct the modern media system, strengthen the construction of infrastructure and establish the media system and comprehensive platforms that integrate television, broadcast, publishing house and network; strengthen the way to supervise the media and apply the national public power to make "the party administrates media". Opinions that harm and overturn the mainstream ideological safety of our country must be controlled and struck; pay attention to the new media methods represented by We Media, actively communicating with the masses on the platform of We Media like WeChat, Weibo and blog to solve the practical problems and win over the masses; actively propagandize the mainstream ideology on all the media transmission platforms and output the mainstream ideology of our country through frequently-used forms like text, video, broadcast, cartoon and games to grasp the speaking right of propaganda.

\section{CONCLUSION}

At present, the discourse expression of the socialist ideology in our country faces a more complicated situation and more severe challenges. Under the current situation, the advancement of the discourse innovation and expression of ideology must firmly base on the ideological theory of $\mathrm{Xi}$ Jinping, profoundly grasp the opinions, connotations and methods, so that the discourse expression of ideology at the new period will be more modernized and popular and closer to people's life.

\section{REFERENCES}

[1] Li Xiaona, Wang Zhigang. The Development of Ideological Theory in Marxism[J/OL].http://www.cssn.cn/mkszy/jp/201310/t20131025_54990 5.shtml, Jan.23, 2013

[2] Huang Shihu, Zhao Jianmei. Mao Zedong's Theory of Ideology and Its Value in the Contemporary Era [J], Truth Seeking, 2010(12): 8-10

[3] Zhang Bo. Research on the Ideological Safety in Our Country in Modern Media [D], Lanzhou University, 2015

[4] Wang Wenhui, Qin Shusheng. Analysis on the Strategic Thought of Ideology of Xi Jinping [J], Theory and Reform, 2016, 01:20-26

[5] Men Xianping. Analysis on the Thought of Xi Jinping about the Construction of the Mainstream Ideology [J], Exploration, 2014(05):814

[6] Yang Jinhai. Thinking on Problems about the Current Ideological Work-Learn the Spirit of Important Address of General Secretary Xi Jinping on the Ideological Work [J], Journal of China Executive Leadership Academy Pudong, 2014(2):10-18

[7] Hong Guangdong, Wang Yonggui. The Development and Thinking of the Current Research on the New Ideas about the Ideological Construction of Xi Jinping [J], Guangxi Social Sciences, 2014,09:4-9

[8] Zhang Yanbin. The Opinions of Xi Jinping on Ideology and Its Value of Times [J], Academic Forum, 2015, 07:12-15

[9] Li Zongjian. New Ideas of Xi Jinping on Ideology since the 18th National Congress of the CPC [J], Socialism Studies, 2016, 02:35-42

[10] Wang Yonghua. Ideas of Xi Jinping in the Ideological Construction [J], Journal of Socialist Theory Guide, 2016, 02:4-7+16

[11] Tang Aijun. The Methodology of Xi Jinping on the Ideological Work [J], Studies on the Socialism with Chinese Characteristics, 2014, 06:3234

[12] Du Renhuai. The Effective Maintenance of Mainstream Media and the Path Selection for the Guarantee of Ideological Safety-Learning the Important Statement of General Secretary Xi Jinping on the Ideological Construction [J], Observation and Reflection, 2015,07:18-22

[13] Gong Yun. Consolidate the Guiding Role of Marxism in the Ideological Field - the 27th Experience in Learning the Important Addresses of General Secretary Xi Jinping [J], Frontline, 2014,01:27-29 